\title{
The Meteorological Society of \\ Japan
}

Scientific Online Letters on the Atmosphere (SOLA)

\section{EARLY ONLINE RELEASE}

This is a PDF of a manuscript that has been peer-reviewed and accepted for publication. As the article has not yet been formatted, copy edited or proofread, the final published version may be different from the early online release.

This pre-publication manuscript may be downloaded, distributed and used under the provisions of the Creative Commons Attribution 4.0 International (CC BY 4.0) license. It may be cited using the DOI below.

The DOI for this manuscript is

DOI: 10.2151/sola. 2020-038.

J-STAGE Advance published date: Oct. 22, 2020

The final manuscript after publication will replace the preliminary version at the above DOI once it is available. 
1 Investigating Aerosol Effects on Maritime Deep Convective Clouds using Satellite and Reanalysis Data

Pradeep Khatri, Hiroaki Ooashi, and Hironobu Iwabuchi

4 Center for Atmospheric and Oceanic Studies, Graduate School of Science, Tohoku 5 University, Sendai, Japan

6

7 Corresponding author: Pradeep Khatri, Center for Atmospheric and Oceanic Studies, 8 Tohoku University, Sendai, Japan, 980-8578, Japan. E-mail:

pradeep.khatri.a3@tohoku.ac.jp. 


\section{Abstract}

2 Aerosol effects on deep convective cloud (DCC) have been recognized as one of the

3 complex subjects in climatic studies because of the difficulty in quantifying the sole effect

4 of aerosols on DCC. The complexity further arises if the atmosphere has very strong

5 temporal and spatial variations such as that of Indo-Pacific Warm Pool (IPWP) region.

6 Considering the strong influence of IPWP region on global climate change and water

7 circulation, we investigated aerosol effects on DCC over this region by using data of

8 2015-2016 El Niño and the 2017-2018 La Niña events. We developed a spectral analysis

9 based framework to identify and decouple the influences of major external factors on

10 aerosol-DCC relationship. We found that temporal variations of aerosols, clouds, and

11 meteorology longer than 2 days' time scale can have larger influences than their diurnal

12 and spatial variations on aerosol-DCC relationship. By removing the effects of those

13 spatial and temporal variations of different scales, the study suggests that aerosols of

14 IPWP region can affect DCC properties with time lags less than $\sim 5$ hours and by

15 increasing cloud-top height, cloud coverage, and DCC number concentration with the

16 increase of aerosols.

17

18

19 


\section{1. Introduction}

2 The increase of cloud droplets due to the increase of aerosols (Twomey, 1977) can

3 inhibit early rain formation and droplet growth (Albrecht, 1989). Under convective 4 conditions, such delay in precipitation simultaneously increases droplet mobility 5 (Heiblum et al., 2016), leading more water mass aloft in the atmosphere. This results the

6 formation of ice particles by releasing latent heat once the freezing level is reached, and

7 then invigorates cloud vertical development and expansion. This phenomenon, known as

8 Aerosol Invigoration Effect AIE (William et al., 2002; Andreae et al., 2004; Khain et al.,

9 2005,2008; Wang, 2005; van den Heever et al., 2006,2011) can have important roles on

10 convection (e.g., Fan et al., 2018), cloud properties (e.g., Koren et al., 2010), and

11 precipitation (e.g., Rosenfeld et al., 2008).

12 The Indo-Pacific Warm Pool (IPWP) region is regarded as a natural laboratory for

13 climate research community because of its impact on global climate and water circulation

14 through atmospheric teleconnection. Deep convective clouds (DCCs) over IPWP can

15 expand up to hundreds of kilometers to have climatic impact on a global scale (Houze,

16 2014), making aerosol-DCC interaction over this region an important aspect in the global

17 climate system. Quantifying aerosol effects on such DCC is an exceptionally challenging

18 task because of the coupling effects of aerosol, radiation, and atmospheric dynamics (Tao

19 et al., 2012). Additionally, the atmospheric variations due to large-scale atmospheric

20 dynamics and radiative processes, i.e., variations of different time scales, such as diurnal,

21 intraseasonal, seasonal, interannual, decadal, and even longer periods (Chang et al., 2004)

22 can add complexity in the study of aerosol-DCC interaction over this region. It is because

23 they can simply overshadow aerosol-DCC interaction occurring in relatively shorter

24 spatial and temporal scales. The aerosol-DCC interaction can be further affected by 
1 atmospheric variations due to small-scale dynamics, i.e., cold pools (e.g., Grant and van

2 den Heever, 2014; Jeon et al., 2018). Since AIE can depend on environmental conditions

3 (e.g.,Khain et al., 2005; Fan et al., 2009; Storer et al., 2010), it is important to identify

4 and decouple the influences of dominant natural phenomena for better understanding

5 aerosol-DCC interaction over this region, which is the main goal of this study.

6 This study is organized as follows: Sections 2 and 3 describe data and methodology;

7 Section 4 provides results and discussion, and Section 5 the conclusion.

9 2. Data

10 We used satellite and reanalysis data over the region of $20^{\circ} \mathrm{S}-20^{\circ} \mathrm{N}$ and $90^{\circ} \mathrm{E}-180^{\circ} \mathrm{E}$

11 for selected months (July, October, December, and January) of 2015-2016 El Niño and

12 the 2017-2018 La Niña events. The cloud properties are derived from Integrated Cloud

13 Analysis System ICAS (Iwabuchi et al., 2016) by using Advanced Himawari Imager

14 (AHI) observed infrared signals combined with the ozone and atmospheric profiles of

15 meteorological data from Modern-Era Retrospective Analysis for Research and

16 Application Version-2 MERRA-2 (Gelaro et al., 2017) and incorporating cloud vertical

17 inhomogeneity characteristics (Khatri et al., 2018). The spatial and temporal resolutions

18 of ICAS cloud products are 2-km (at nadir) and 10 minutes, respectively. We further

19 used MERRA-2 aerosol (time-averaged) and meteorological (instantaneous) data.

20 MERRA-2 has a spatial resolution of $0.5^{\circ}$ (latitude)x $0.625^{\circ}$ (longitude) and the temporal

21 resolutions are 1 hour and 3 hours for aerosol and meteorological products. The

22 instantaneous meteorological parameters were interpolated in temporal domain from two

23 pre- and post-adjacent observations; whereas, aerosol data of 1 hour resolution were used. 
1 Both meteorological and aerosol data were linearly interpolated at spatial domain

2 matching with cloud observation.

3 From high-level cloud products with cloud optical thickness $(\mathrm{COT})>0.1$ and cloud-

4 top height $(\mathrm{CTH})>10 \mathrm{~km}$, which are reasonable values for minimum limits of thin anvil

5 COT (e.g., Garnier et al., 2012) and DCC top height (e.g.,Chae et al., 2011), DCC was

6 detected using a Detect and Spread technique (Boer and Ramanathan, 1997). Though

7 DCCs were not actually circular in shape, for convenience, an equivalent radius $R_{E Q}$ of

8 DCC was calculated from the total area $(A)$ of DCC by $\sqrt{ }(A / \pi)$. DCC number density

$9(N)$, i.e., DCC counts per unit area $\left(\mathrm{km}^{2}\right)$, was calculated by normalizing total DCC counts

10 by total pixel areas corresponding to study region.

11 Since aerosol number concentration rather than aerosol optical thickness (AOT) can

12 represent cloud condensation nuclei $(\mathrm{CCN})$ concentration more reasonably, we used

13 aerosol index (AI), a product of AOD and Angstrom exponent (AE), as a proxy of aerosol

14 number concentration (Nakajima et al., 2001). Primarily, sea-salt aerosols are dominant

15 over our study region, but aerosols of biomass burning are also profound, especially

16 during October (Eck et al., 2019). Convective Available Potential Energy (CAPE), an

17 indicator of atmospheric instability with higher positive value indicating more unstable

18 atmosphere, was calculated using MERRA-2 data by integrating the buoyancy of air

19 parcel from the level of free convection to the equilibrium level. Vertical wind shear

20 (VWS) was calculated as the difference between the mean low-level (925 and $850 \mathrm{hPa}$ )

21 and high-level (200 hPa) wind speeds (Chakraborty et al., 2016). We further used relative

22 humidity at $850 \mathrm{hPa}\left(\mathrm{RH}_{850 \mathrm{hpa}}\right)$ and updraft velocity at $500 \mathrm{hPa}\left(\omega_{500 \mathrm{hpa}}\right)$ considering the

23 important roles of water vapor of low-level atmosphere on the DCC development and

24 mid-level atmospheric updraft velocity on cloud-top height and anvil cloud expansion. 


\section{3. Study method}

\section{$3 \quad 3.1$ Removal of the effects of external factors}

4 Firstly, we binned data to a relatively coarse grid of $1^{\circ}$ (latitude) $\times 1.25^{\circ}$ (longitude) to

5 reasonably undermine the effect of non-collocated observations of aerosols and clouds in

6 the study of aerosol indirect effect (e.g., Anderson et al., 2003; Avey et al., 2007). For

7 each grid, we performed arithmetic averaging for aerosol and meteorological data, and

8 weighted averaging for cloud properties with cloud coverage as the weight.

9 Secondly, for each month, we filled the missing data, which may result due to retrieval

10 failure and/or low quality, in temporal and spatial domains by cubic spline interpolation

11 before applying a 3-dimensional fast Fourier transform (FFT). This allowed us to convert

12 the temporal domain of each spatial box into frequency (cycle/day) domain. The

13 frequencies lower than 0.2 cycle/day for aerosol and 0.4 cycle/day for other data

14 (meteorological fields and clouds) were removed by using high-pass filters. They were

15 then transferred back to time series by using an inverse FFT, and data filled up before

16 FFT were removed. Those frequencies mentioned above were removed assuming that

17 they were the results of some meteorological and natural phenomena occurring over the study region as summarized in Supplement I. Thus, our data can correspond the variations associated with relatively short-period local-scale fluctuations.

Thirdly, for each month, we removed the diurnal variations by subtracting hourly

21 averages from the instantaneous values. It is because DCC modification due to solar

22 insolation time and land-sea temperature difference can be prominent even without the 23 effect of aerosols. 
1 Finally, we removed the spatial contrasts by subtracting the mean values of each spatial

2 box from instantaneous values. The spatial contrast can arise depending on the distance

3 of DCC from land surface and/or due to region specific natural phenomenon. The external

4 factors stated onward are low-frequency, diurnal, and spatial variations.

5 When performing a sensitivity study, we removed the effect(s) of factor(s) that

6 was(were) concerned. For example, anomalies were calculated without excluding the

7 effects of diurnal and low-frequency variations while studying the sole effect of spatial 8 variation.

$10 \quad 3.2$ Timescale for AIE and composite analysis

11 DCCs are affected by aerosols and environment via dynamical, microphysical, and 12 radiative processes. Thus, a time delay can be expected for changes in DCC properties 13 due to change in the atmosphere. To understand such time delay, we analyzed DCC 14 properties $(y)$ of observation time $t_{y}$ with AI data $(x)$ of observation time $t_{x}=t_{y}-\Delta t$, where $15 \Delta t$ is time difference between cloud and aerosol observations. AIs within $\pm 2 \sigma_{x}$ of the mean 16 value, where $\sigma_{x}$ is the standard deviation, were divided into 2000 bins to average AIs of 17 each bin and DCC properties corresponding to them, and then to calculate regression 18 coefficient $\partial y / \partial x$ using a least square regression method. A change in $y$ for a $\sigma_{x}$ change in $19 x$ was calculated as $\Delta y=\partial y / \partial x \sigma_{x}$.

20 We further used a composite analysis to study AIE after eliminating the effects of 21 external factors mentioned above. First, we calculated the anomalies of AI within $\pm 2 \sigma_{x}$ of 22 the mean values and DCC properties corresponding to them. For 10 bins of AI anomalies 23 ranging from -0.1 to 0.1 (bin width $=0.02$ ), the corresponding DCC anomalies were used 
1 to calculate the mean and $95 \%$ confidence interval values by using a bootstrap method as

2 summarized in Appendix II.

3

\section{4. Results and Discussion}

\section{$5 \quad 4.1$ Effects of external factors}

6 We performed a sensitivity study by eliminating the effect of each factor outlined in

7 Section 3.1 individually and collectively. Figure 1 shows changes in $\Delta R_{\mathrm{EQ}}$ for $1-\sigma$ change

8 in AI for different time lags between aerosol and cloud observations. The mean $R_{\mathrm{EQ}}$ for

9 data of our study was $38.3 \mathrm{~km}$. For the case without eliminating the effect of any factor,

$10 \Delta R_{\mathrm{EQ}}$ was nearly constant regardless of time lag. This result might be mistakenly

11 interpreted as no response of AI of different time lags on cloud properties. In this case,

12 the external factors, including low-frequency variations with period longer than 48 hours

13 (see Supplement I), simply overshadow aerosol-cloud interaction process of lifetime

14 shorter than 48 hours. When the effect of diurnal variation was removed, $\Delta R_{\mathrm{EQ}}$ responded

15 with the change of lag hour, suggesting the influence of diurnal variation in aerosol-DCC

16 relationship. The effect of diurnal variation seems to be larger than effects of other factors,

17 which is plausibly due to the strong influence of solar insolation time and land-sea surface

18 temperature difference on diurnal cycle of DCC than that for aerosols. Next, removal of

19 the spatial variation effect can be seen to change the $\Delta R_{\mathrm{EQ}}-$ lag hour relationship as well.

20 A small peak appeared at lag hour of $\sim 6$, indicating that spatial variation was capable to

21 influence aerosol-DCC relationship as well. However, we noted a negative $\Delta R_{\mathrm{EQ}}$ for such

22 peak value. This negative $\Delta R_{\mathrm{EQ}}$, i.e., negative $\partial R_{\mathrm{EQ}} / \partial A I^{*} \sigma_{A I}$ (see Section 3.2), is possible

23 if relatively larger $R_{E Q}$ values are affected significantly than smaller $R_{E Q}$ values while 
1 removing spatial variation effects. The spatial mean values of $R_{E Q}$ used to remove spatial

2 variation effect of native $R_{E Q}$ values are non-uniform with larger mean values for regions

3 that have larger native $R_{E Q}$ values. Thus, while removing spatial variation effect,

4 relatively larger native $R_{E Q}$ values can be affected significantly than smaller native $R_{E Q}$

5 values to give a negative $\partial R_{\mathrm{EQ}} / \partial A I$ and then negative $\Delta R_{\mathrm{EQ}}$. In contrast, removal of low-

6 frequency variation produced a peak after $\sim 3$ hours. The dominant DCCs over our study

7 region were with $R_{\mathrm{EQ}}$ of $\sim 30-40 \mathrm{~km}$, whose typical lifetime could be $\sim 6$ hours according

8 to Inoue et al. (2009). Therefore, the noted peak with time lag less than 6 hours seems

9 reasonable, indicating more effectiveness of the removal of low-frequency variation.

10 We also performed a sensitivity study by removing the low-frequency at first, followed

11 by diurnal and spatial variations, which showed no significant difference in $\Delta R_{\mathrm{EQ}}-\mathrm{lag}$

12 hour relationship as compared to the removal of low-frequency variation alone. This

13 indicated low-frequency variation as the most important factor among the three

14 considered in this study. The results onward correspond to the removal of low-frequency,

15 diurnal, and spatial variations.

16 The importance and necessity of removing the effects of such external factors are

17 further emphasized in Figure 2, which shows the correlations among AI and different

18 meteorological parameters. If strong dependencies (correlations) among meteorological

19 parameters exist, one may expect a severe meteorological condition affecting DCC

20 promptly by overshadowing aerosol effect, and vice versa. After removing the external

21 factors, we noted weaker relationships among the meteorological parameters (Figure 2b)

22 than before (Figure 2a). Such a weak meteorological field can be more favorable and

23 reliable for evaluating aerosol effects on DCC. Note that those meteorological parameters

24 correspond to relatively coarse grid giving overall view of relatively larger area. 
1 Especially, w 500hpa gives an overall view on the distribution of both ascending and

2 descending motions. This plausibly explains relatively poor correlation between CAPE

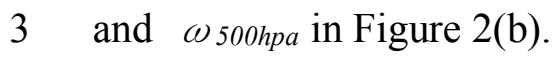

\section{$5 \quad 4.2$ Timescale for AIE}

Figure 3 shows the differences in DCC properties $\left(\triangle R_{E Q}, \triangle C T H\right.$, and $\triangle N$ ) for 1- $\sigma$

7 (0.023) change in AI after eliminating the effects of all factors. The mean values of $R_{E Q}$, $8 C T H$, and $N$ for data of this study were $38.3 \mathrm{~km}, 13.1 \mathrm{~km}$ and $1.1 \times 10^{-4} \mathrm{~km}^{-2}$, respectively.

9 The peak values of $\triangle R_{E Q}, \triangle C T H$, and $\triangle N$, determined by generating fine resolution 10 data via cubic spline fitting, were for time lags of $1,-1.5$ and 4.5 hours, respectively. We 11 speculate that precipitation effect was important for negative time lag for $\triangle C T H$. Kubar 12 and Hartmann (2008) suggested that heavily precipitating clouds have higher CTH than 13 moderately precipitating or non-precipitating high clouds. $\triangle C T H$ was derived as $14 \partial C T H / \partial A I^{*} \sigma_{A I}$ (see Section 3.2). Thus, if precipitating clouds wash out aerosols, a 15 negative time lag is prominent, which can be weakly compensated by possibly positive 16 time lag for non-precipitating clouds to result overall negative time lag in a composite 17 analysis. Gasparini et al. (2019) using a modelling study suggested that clouds start to 18 spread horizontally after reaching the maximum height, indicating that time lag for $\triangle$ $19 C T H$ is shorter than that for $\triangle R_{E Q}$. Though negative in value, our observation-based 20 results are consistent with modelling study of Gasparini et al. (2019). According to Figure 3 , we suggest that the optimum time lag for aerosol effects on DCC is less than $\sim 5$ hours. 
$1 \quad 4.3 \mathrm{AIE}$

2 Figure 4 shows the relationships between AI and DCC properties $\left(R_{E Q}, C T H\right.$, and $\left.N\right)$ 3 anomalies with $95 \%$ confidence bands. Figure 4 suggests that aerosols can invigorate 4 DCCs over our study region. Except for exceptionally dominant absorbing aerosols (e.g., 5 Jiang et al., 2018), aerosols can increase $C T H$ and DCC coverage via AIE as discussed in

6 Section 1. Such results could be achieved for our study region after removing the effects

7 of external factors mentioned in Section 4.1. Though AIE in forms of $C T H$ and $R_{E Q}$ 8 increments has been widely studied, AIE in the form of $N$ modification is still limited in 9 number. Xue et al. (2008) suggested that an increase of aerosols can increase $N$ of shallow 10 cumulus clouds using large eddy simulation. To the best of our knowledge, there are no 11 observation-based studies to shed further light on aerosol effects on $N$. Figure 4(c) 12 suggests that aerosol increment also leads to increasing $N$. Below the baseline (mean) 13 value of AI, the change in $N$ was not significant; however, it changed rapidly after the 14 baseline value. Tracking of DCC is difficult because DCC frequently undergoes 15 aggregation and decomposition. Further, tracking of concentrated DCCs can be more difficult than unconcentrated DCCs. Probably, this may lead tracked DCCs broadly into

17 two groups of low and high concentrations. Another speculation is that DCCs might have 18 occurred over the study region by broadly dividing into two groups of relatively low and 19 high densities. We speculate they could be plausible reasons for rapid change of $N$ after 20 the baseline value of AI in Figure 4(c). We suggest two possible reasons for increasing $N$ 21 with increasing AI. First, precipitation suppression via AIE (see Section 1) can suppress atmospheric stability, generating a favorable condition to seed a new convective cloud

23 and/or to delay the dissipation of existing DCC. Second, an increase in updraft velocity 24 via AIE is also suggested to increase downdraft velocity as a compensation (Zhou et al., 
1 2017), which can form a cold pool. Such cool pool formation can make it favorable for a

2 next-generation convection (Houze Jr, 2014; Torri et al., 2015; van den Heever et al., 3 2006; Tao et al., 2007).

4

\section{5. Conclusions}

6 This study investigated aerosol effects on DCC over IPWP region by identifying and 7 decoupling important factors that could distort relationship between aerosol and DCC 8 properties. The study used data of 2015-2016 El Niño and the 2017-2018 La Niña events.

9 The spectral analysis suggested that clouds, aerosols, and meteorological parameters over 10 the IPWP region were strongly correlated with atmospheric variations of different spatio11 temporal scales. Our sensitivity study indicated that such spatio-temporal variations could 12 significantly affect the quantification of aerosol effect on DCC. Specifically, we found 13 that the influence of low-frequency variations with periods longer than 2 days was 14 stronger than that of diurnal and spatial variations. After eliminating the effects of those 15 external factors, we noted the maximum effects of increased aerosols on cloud properties $16\left(C T H, R_{E Q}\right.$, and $\left.N\right)$ for time lags less than $\sim 5$ hours. Those cloud properties were noted to 17 increase with increased AI, suggesting aerosol invigoration effect over the IPWP region. 


\section{Acknowledgements}

2 This study is supported by the $1^{\text {st }}$ Research Announcement (RA) on the Earth 3 Observations of the Japan Aerospace Exploration Agency (JAXA; PI no. RA1R306), a

4 Grant-in-Aid for Scientific Research (C) 17K05650 from Japan Society for the Promotion 5 of Science (JSPS), and "Virtual Laboratory for Diagnosing the Earth's Climate System" 6 program of MEXT, Japan. The Himawari- 8 and MERRA-2 data used in this study are 7 obtained from the National Institute of Information and Communication Technology 8 (NICT) and National Aeronautics and Space Administration (NASA), respectively. The

9 authors would like to express sincere thanks to anonymous reviewers for constructive 10 comments.

Supplements

13 Supplement I: Additional information for study region and data.

14 Supplement II: Additional information for data analysis method 


\section{$1 \quad$ References}

2 Albrecht, B. A., 1989: Aerosols, cloud microphysics, and fractional cloudiness. Science, 245, 1227-1230, doi: 10.1126/science.245.4923.1227.

Anderson, T. L., R. J. Charlson, D. M. Winker, J. A. Ogren, and K. Holmén, 2003: Mesoscale variations of tropospheric aerosols. J. Atmos. Sci., 60, 119136 ,doi:10.1175/1520-0469(2003)060\%3C0119:MVOTA\%3E2.0.CO;2.

Andreae, M. O, D. Rosenfeld, P. Artaxo, A. A. Costa, G. P. Frank, K. M. Longo, and M. A. F. Silva-Dias, 2004: Smoking rain clouds over Amazon. Science, 303, 13371342, doi:10.1126/science.1092779.

Avey, L.,T. J. Garrett, and A. Stohl, 2007: Evaluation of the aerosol indirect effect using satellite, tracer transport model, and aircraft data from the International Consortium for Atmospheric Research on Transport and Transformation. J. Geophys. Res., 112,

Boer, E. and V. Ramanathan, 1997: Lagrangian approach for deriving cloud doi:10.1029/2006JD007581. characteristics from satellite observations and its implications to cloud parameterization. J. Geophys. Res., 102, 21383-21399, doi: 10.1029/97JD00930.

17 Chakraborty, S., R. Fu, S. T. Massie, and G. Stephens, 2016: Relative influence of meteorologi- cal conditions and aerosols on the lifetime of mesoscale convective systems. Proc. Natl. Acad. Sci., 113, 7426-7431, doi: 10.1073/pnas.1601935113. 
convective clouds on temperature, water vapor, and dehydration in the tropical tropopause layer (TTL). Atmos. Chem. Phys., 11, 3811-3821, doi:10.5194/acp-113811-2011, 2011.

Chang, C. P., 2004: East Asian Monsoon. World Scientific Series on Meteorology of East Asia, 564pp.

Eck, T.F., B. N. Holben, D. M. Giles, I. Slutsker, A. Sinyuk, J. S. Schafer, A. Smirnov, M. Sorokin, J. S. Reid, A. M. Sayer, N. C. Hsu, Y. R. Shi, R. C. Levy, A. Lyapustin, M. A. Rahman, S. - C. Liew, S. V. S. Cortijo, T. Li, D. Kalbermatter, K. L. Keong, M. E. Yuggotomo, F. Aditya, M. Mohamad, M. Mahmud, T. K. Chong, H. - S. Lim, Y. E. Choon, G. Deranadyan, S. D. A. Kusumaningtyas, and E. Aldrian, 2019: AERONET remotely sensed measurements and retrievals of biomass burning aerosol optical properties during the 2015 Indonesian burning season. J. Geophys. Res., 124, doi: 10.1029/2018JD030182.

Fan, J, T. Yuan, J. M. Comstock, S. Ghan, A. Khain, L. R. Leung, Z. Li, V. J. Martins, and M. Ovchinnikov, 2009: Dominant role by vertical wind shear in regulating aerosol effects on deep convective clouds. J. Geophys. Res., 114, doi:10.1029/2009JD012352.

Fan, J., L. R. Leung, D. Rosenfeld, Q. Chen, Z. Li, J. Zhang, and H. Yan ,2013: Microphysical effects determine macrophysical response for aerosol impacts on deep convective clouds. Proc. Natl. Acad. Sci., 110, E4581-E4590, doi:10.1073/pnas.1316830110. 
1 Fan. J., D. Rosenfeld, Y. Zhang, S. E. Giangrande, Z. Li, L. A. T. Machado, S. T. Martin, 2 Y. Yang, J. Wang, P. Artaxo, H. M. J. Barbosa, R. C. Braga, J. M. Comstock, Z. 3 Feng, W. Gao1, H. B. Gome, F. Mei, C. Pöhlker, M. L. Pöhlker, U. Pöschl1, and R. A. F. de Souza 2018: Substantial convection and precipitation enhancements by ultrafine aerosol particles.

Science,

359 , 411-418, doi:10.1126/science.aan8461pmid:29371462.

7 Garnier, A., J. Pelon, P. Dubuisson, M. Faivre, O. Chomette, N. Pascal, and D. P. Kratz, 2012: Retrieval of cloud properties using CALIPSO imaging infrared radiometer. Part I: Effective emissivity and optical depth. J. Appl. Meteorol. Climatol., 51, 1407-1425, doi:10.1175/JAMC-D-11-0220.1.

11 Gasparini, B., P. N. Blossey, D. L. Hartmann, G. Lin, and J. Fan: 2019: What Drives the Life Cycle of Tropical Anvil Clouds? J. Adv. Model. Earth Syst., 11, 2586-2605, doi:

Gelaro, R., W. McCarty, M. J. Su' arez, R. Todling, A. Molod, L. Takacs, C. A. Randles, A. Dar- menov, M. G. Bosilovich, R. Reichle, et al. , 2017: The modern-era retrospective analysis for research and applications, version 2 (MERRA-2). J. Clim., 30, 5419-5454, doi: 10.1175/JCLI-D-16-0758.1.

Grant, L. D. and S. C. van den Heever, 2014: Aerosol - cloud - land surface interactions within tropical sea breeze convection. J. Geophys. Res., 119, 8340-8361, doi:10.1002/2014JD021912. 
1 Heiblum, R. H., Altaratz, O., Koren, I., Feingold, G., Kostinski, A. B., Khain, A.

2 P., Ovchinnikov, M., Fredj, E., Dagan, G., Pinto, L., Yaish, R., and Chen, Q., 2016:

3 Characterization of cumulus cloud fields using trajectories in the center of gravity

4 versus water mass phase space: 2. Aerosol effects on warm convective clouds. $J$.

$5 \quad$ Geophys. Res., 121, 6356-6373, doi: 10.1002/2015JD024193.

$6 \quad$ Houze Jr, R. A., 2014: Cloud Dynamics, Second Edition. Academic Press, 496 pp.

7 Inoue, T., D. Vila, K. Rajendran, A. Hamada, X. Wu, and L. A. Machado,2009: Life cycle 8 of deep convective systems over the eastern tropical Pacific observed by TRMM and 9 GOES-W. J. Meteor. Soc. Japan, 87, 381-391. doi: 10.2151/jmsj.87A.381.

10 Iwabuchi, H., M. Saito, Y. Tokoro, N. S. Putri, and M. Sekiguchi, 2016: Retrieval of 11 radiative and microphysical properties of clouds from multispectral infrared 12 measurements. PEPS, 3, doi:10.1186/s40645-016-0108-3.

13 Jeon, Y.-L., S. Moon, H. Lee, J.-J. Baik, and J. Lkhamjav, 2018: Non-monotonic 14 dependencies of cloud microphysics and precipitation on aerosol loading in deep convective clouds: A case study using the WRF model with bin 16 microphysics. Atmosphere, 9, doi:10.3390/atmos9110434.

17 Khain, A. P., D. Rosenfeld, and A. Pokrovsky, 2005: Aerosol impact on the dynamics and 18 microphysics of deep convective clouds. Q. J. R. Meteorol. Soc., 131, 2639-2663, doi:10.1256/qj.04.62.

Khain, A. P., N. BenMoshe, and A. Pokrovsky, 2008: Factors Determining the Impact of Aerosols on Surface Precipitation from Clouds: An Attempt at Classification. $J$. Atmos. Sci., 65, 1721-1748, doi:10.1175/2007JAS2515.1. 
1 Khatri, P., H. Iwabuchi, and M. Saito, 2018: Vertical profiles of ice cloud microphysical properties and their impacts on cloud retrieval using thermal infrared measurement. J. Geophys. Res., 123, doi: 10.1029/2017JD028165.

Koren, I., G. Feingold, and and L. Remer, 2010: The invigoration of deep convective clouds over the Atlantic: aerosol effect, meteorology or retrieval artifact? Atmos. Chem. Phys. 10, 8855-8872, doi: 10.5194/acp-10-8855-2010.

Kubar, T. L. and D. L. Hartmann, 2008: Vertical structure of tropical oceanic convective clouds and its relation to precipitation. Geophys. Res. Lett., 35, L03804. doi: 10.1029/2007GL032811.

Nakajima, T., A. Higurashi, K. Kawamoto, and J. E. Penner, 2001: A possible correlation between satellite-derived cloud and aerosol microphysical parameters. Geophys. Res. Lett., 28, 1171-1174. doi: 10.1029/2000GL012186.

Rosenfeld, D., U. Lohmann, G. B. Raga, C. D. O’Dowd, M. Kulmala, S. Fuzzi, A. Reissell, and M. O. Andreae ,2008: Flood or drought: how do aerosols affect precipitation? Science, 321, , 1309-1313,doi: 10.1126/science.1160606.

Storer, R. L., S. C. van Den Heever, and G. L. Stephens, 2010: Modeling aerosol impacts on convective storms in different environments. J. Atmos. Sci., 67, 3904-3915, doi: 10.1175/2010JAS3363.1.

Tao, W. -K, X. Li, A. Khain, T. Matsui, S. Lang, and J. Simpson, 2007: Role of atmospheric aerosol concentration on deep convective precipitation: cloud-resolving model simulations. J. Geophys. Res., 112, doi: 10.1029/2007JD008728 
1 Tao,W, -K, J. P, Chen, Z. Li, C. Wang, and C. Zhang, 2012: Impact of aerosols on and precipitation. Rev. Geophys., 50, doi:10.1029/2011RG000369.

Torri, G., Z. Kuang, and Y. Tian, 2015: Mechanisms for convection triggering by cold pools. Geophys. Res. Lett., 42, 1943-1950. doi: 10.1002/2015GL063227.

Twomey, S. ,1977: The Influence of Pollution on the Shortwave Albedo of Clouds. $J$. Atmos. Sci., $\quad$ 34, 1149-1152, doi:10.1175/15200469(1977)034<1149:TIOPOT $>2.0 . C O ; 2$.

van den Heever, S. C., G. G. Carrió, W. R. Cotton, P. J. DeMott, and A. J. Prenni, 2006: Impacts of Nucleating Aerosol on Florida Storms. Part I: Mesoscale Simulations. $J$. Atmos. Sci., 63, 1752-1775, doi:10.1175/JAS3713.1.

van den Heever, S. C., G. L. Stephens, and N. B. Wood, 2011: Aerosol Indirect Effects on Tropical Convection Characteristics under Conditions of Radiative-Convective Equilibrium. J. Atmos. Sci., 68, 699-718, doi:10.1175/2010JAS3603.1.

Wang, C., 2005: A modeling study of the response of tropical deep convection to the increase of cloud condensation nuclei concentration: 1. Dynamics and microphysics. J. Geophys. Res., 110, 1-16, doi:10.1029/2004JD005720.

Williams, E., D. Rosenfeld, N. Madden, J. Gerlach, N. Gears, L. Atkinson, N. Dunnemann, G. Frostrom, M. Antonio, B. Biazon, R. Camargo, H. Franca, A. Gomes, M. Lima, R. Machado, S. Manhaes, L. Nachtigall, H. Piva, W. Quintiliano, L. Machado, P. Artaxo, G. Roberts, N. Renno, R. Blakeslee, J. Bailey, D. Boccippio, A. Betts, D. Wolff, B. Roy, J. Halverson, T. Rickenbach, J. Fuentes, and E. Avelino, 2002: Contrasting 
convective regimes over the Amazon: Implications for cloud electrification. $J$. Geophys. Res., 107, doi:10.1029/2001JD000380.

3 Xue, H., G. Feingold, and B. Stevens, 2008: Aerosol effects on clouds, precipitation, and 4 the organization of shallow cumulus convection. J. Atmos. Sci., 65 , 392-406, doi: 10.1175/2007JAS2428.1. effects on the development of cumulus clouds over the Tibetan Plateau. Atmos. Chem. Phys., 17, 7423-7434, doi: 10.5194/acp-2017-148.

9

10

11

12

13

14

15

16

17

18

19

20 


\section{List of Figure Captions}

2 Figure 1. Changes in equivalent radius of DCC $\left(R_{\mathrm{EQ}}\right)$ for $1-\sigma$ change in AI before and

3 after eliminating temporal and spatial variations of aerosols, clouds, and meteorological

4 parameters for combination of AI and cloud data of different time lags. The time lag refers

5 to the difference between cloud and aerosol observation times.

6 Figure 2. Correlation coefficient (\%) among different atmospheric parameters (AI:

7 aerosol index, CAPE: convective available potential energy, $\mathrm{RH}_{850}$ : relative humidity at

8850 hpa, VWS: vertical wind shear, $\omega$ 500: updraft velocity at $500 \mathrm{hpa}$ ) for (a) before and

9 (b) after removal of temporal and spatial variations in data set.

10 Figure 3. Differences in cloud-top height $(\mathrm{CTH})$, equivalent radius $\left(R_{\mathrm{EQ}}\right)$ and number

11 density of DCC for $1-\sigma$ change in AI after eliminating spatial and temporal variations.

12 The time lag refers to the difference between cloud and aerosol observation times.

13 Figure 4. Relationships of $\mathrm{AI}$ anomaly with (a) equivalent radius $\left(R_{\mathrm{EQ}}\right)$, (b) cloud-top

14 height $(\mathrm{CTH})$, and (c) number density $(N)$ of DCC after eliminating spatial and temporal

15 variations. The data correspond to the time lag of 3 hours. The shaded area shows $95 \%$

16 confidence interval.

17

18 

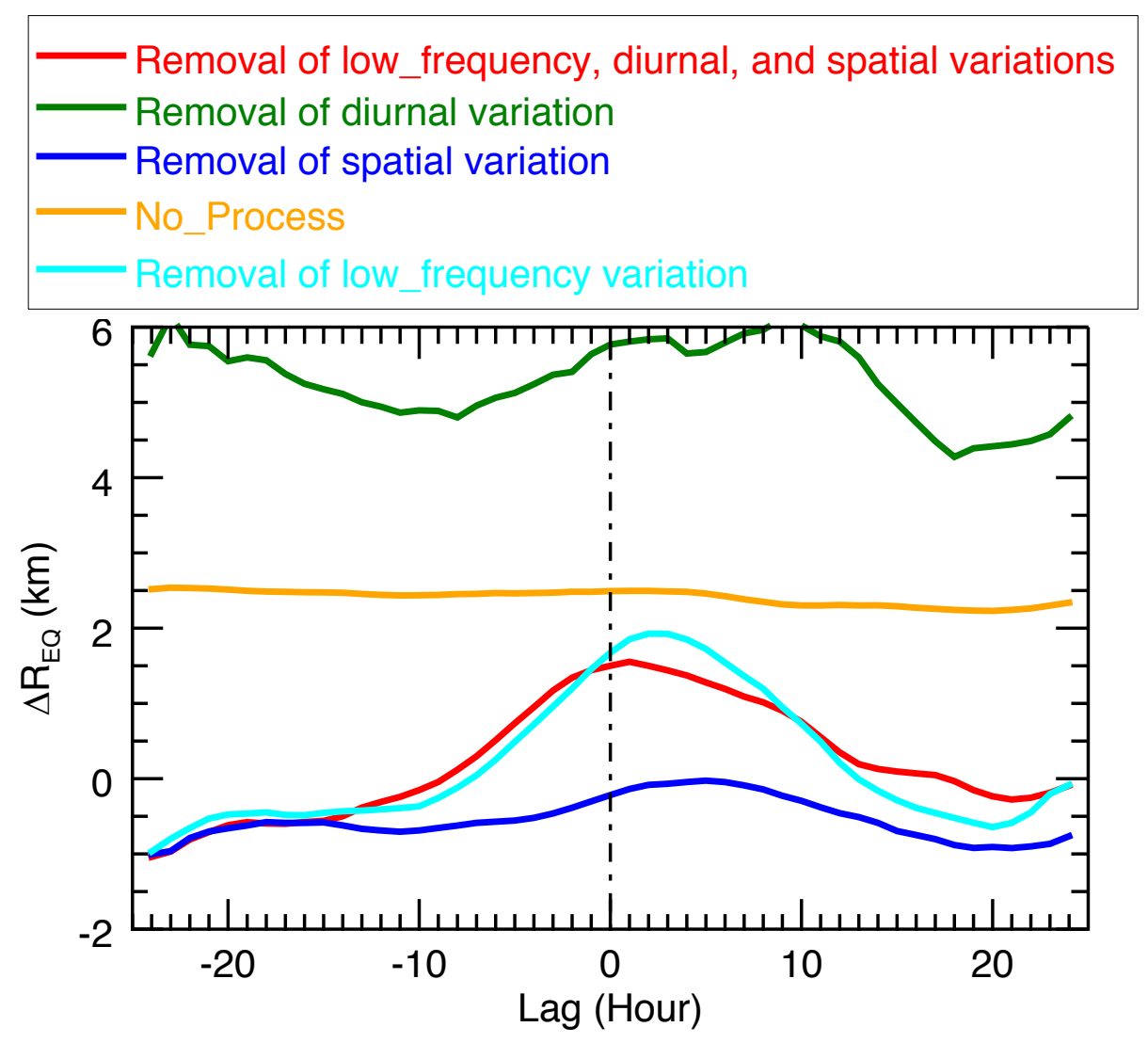

1

2 Figure 1. Changes in equivalent radius of $\mathrm{DCC}\left(R_{\mathrm{EQ}}\right)$ for $1-\sigma$ change in AI before and

3 after eliminating temporal and spatial variations of aerosols, clouds, and meteorological

4 parameters for combination of AI and cloud data of different time lags. The time lag refers

5 to the difference between cloud and aerosol observation times.

6

7

8

9

10

11 
No_Process

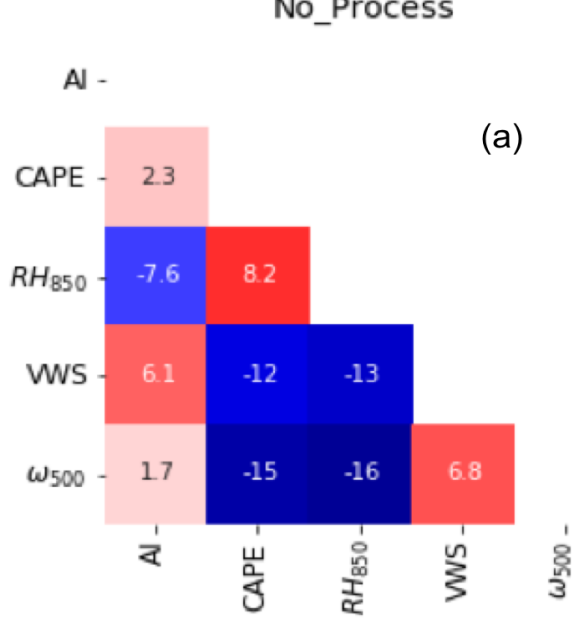

All (Temporal+Spatial)

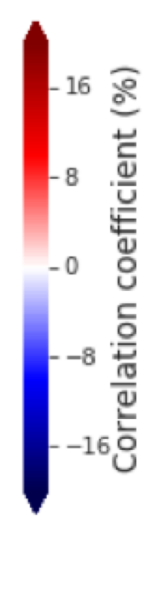

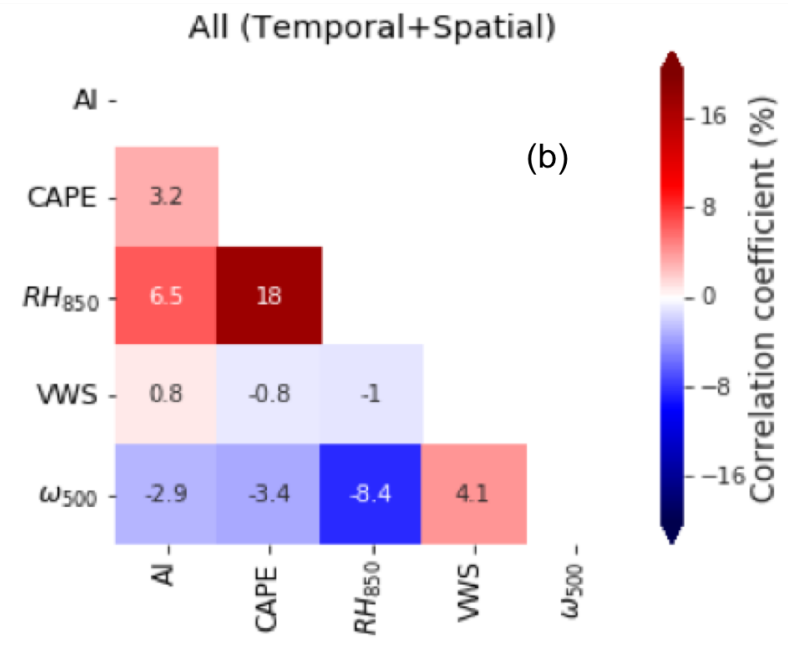

3 Figure 2. Correlation coefficient (\%) among different atmospheric parameters (AI:

4 aerosol index, CAPE: convective available potential energy, $\mathrm{RH}_{850}$ : relative humidity at

5850 hpa, VWS: vertical wind shear, $\omega$ 500: updraft velocity at $500 \mathrm{hpa}$ ) for (a) before and

6 (b) after removal of temporal and spatial variations in data set.

7

8

9

10

11

12

13

14

15

16

17 


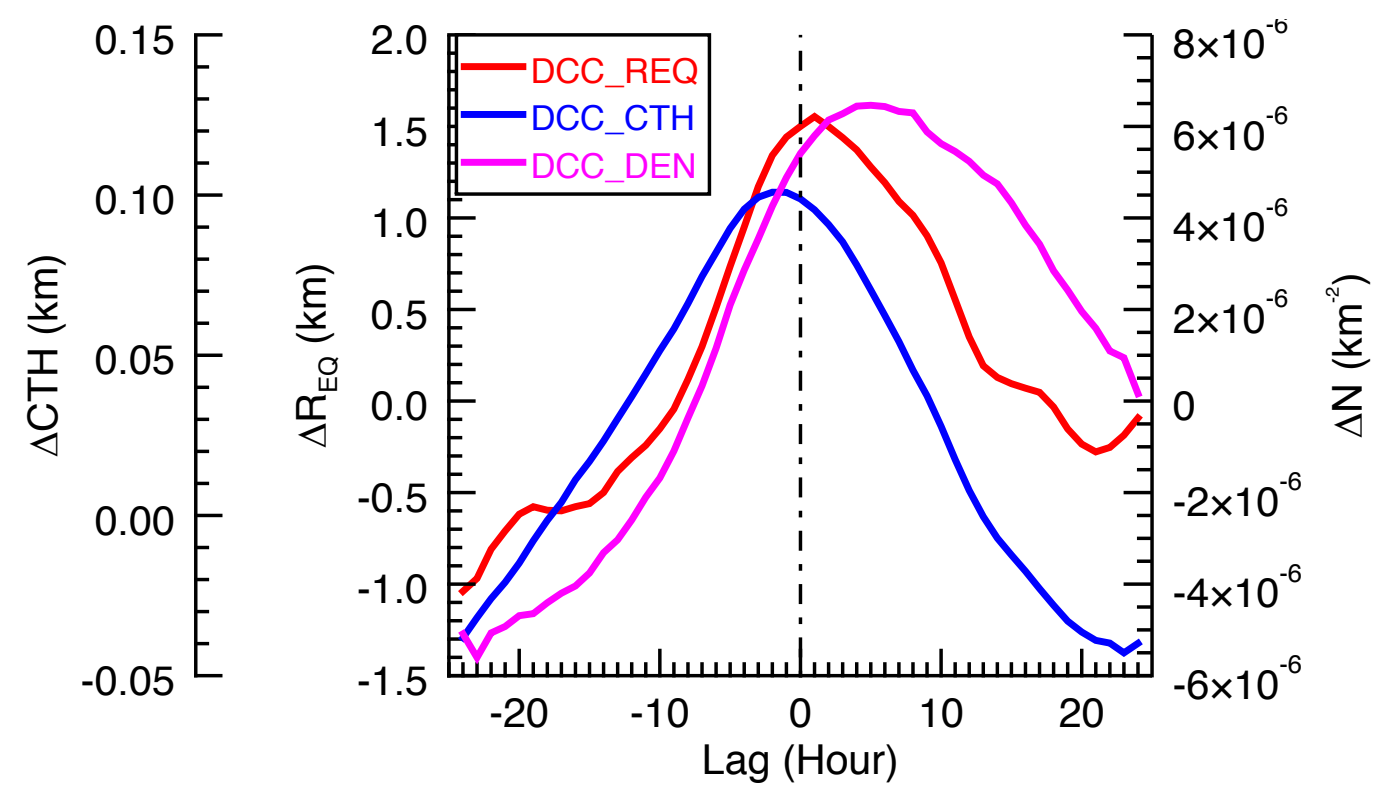

3 Figure 3. Differences in cloud-top height $(\mathrm{CTH})$, equivalent radius $\left(R_{\mathrm{EQ}}\right)$ and number

4 density of DCC for $1-\sigma$ change in AI after eliminating spatial and temporal variations.

5 The time lag refers to the difference between cloud and aerosol observation times.

6

7

8

9 

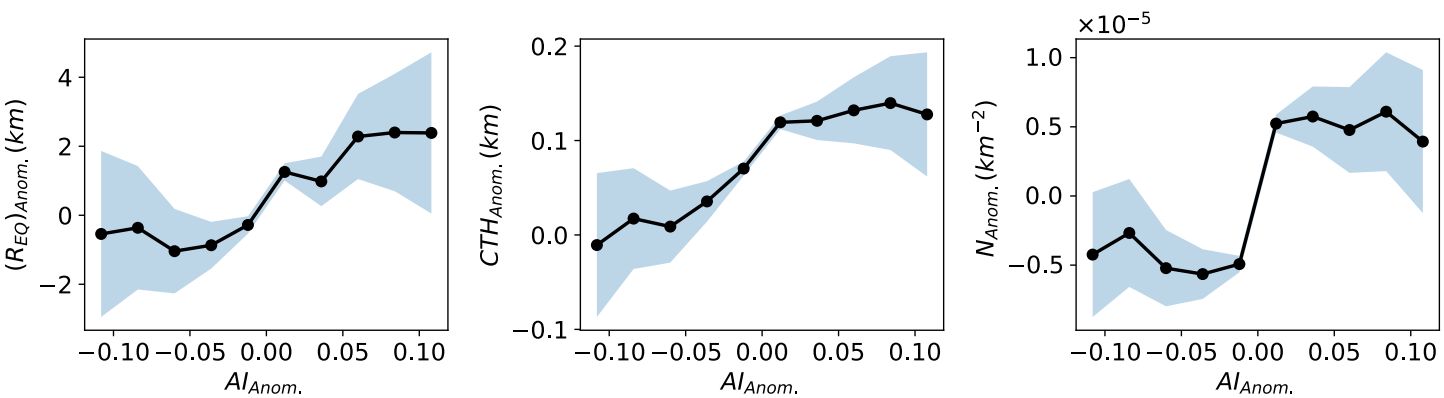

2 Figure 4. Relationships of $\mathrm{AI}$ anomaly with (a) equivalent radius $\left(R_{\mathrm{EQ}}\right)$, (b) cloud-top

3 height $(\mathrm{CTH})$, and (c) number density $(N)$ of DCC after eliminating spatial and temporal

4 variations. The data correspond to the time lag of 3 hours. The shaded area shows $95 \%$

5 confidence interval.

6

7

8 
1 Supplement I: Spatio-temporal variations of aerosols, clouds, and meteorological 2 parameters over the study region

3 Below we briefly highlight the variations of aerosols, clouds, and meteorological 4 parameters over our study region by analyzing one-month data of July 2015 . We binned 5 the data with a spatial resolution of $2^{\circ}$ (longitude) $\times 2.5^{\circ}$ (latitude) and a temporal 6 resolution of 1 hour.

7

\section{S1. Spatial distributions}

9 Figure S1 shows the spatial distributions of meteorological parameters (CAPE, $10 \mathrm{RH}_{850 \mathrm{hpa}}$, VWS, and $\omega_{500 \mathrm{hpa}}$ ), DCC properties (DCC fraction and DCC number density), 11 and AI. CAPE and $\mathrm{RH}_{850}$ are high around Intertropical Convergence Zone (ITCZ; 10$\left.1220^{\circ} \mathrm{N}, 135-180^{\circ} \mathrm{E}\right)$ and South Pacific Convergence Zone (SPCZ; $\left.10-5^{\circ} \mathrm{S}, 160^{\circ}-180^{\circ} \mathrm{E}\right)$, 13 indicating unstable and humid atmosphere. Both regions are also characterized by 14 negative values of VWS and $\omega_{500 \mathrm{hpa}}$. Similarly, Asian monsoon region $\left(0-10^{\circ} \mathrm{N}, 90-\right.$ $15120^{\circ} \mathrm{E}$ ) is characterized by high values of CAPE, $\mathrm{RH}_{850 \mathrm{hpa}}$, and VWS; and negative values 16 of $\omega_{500 \mathrm{hpa}}$, indicating unstable atmosphere with large wind shear. The DCC fraction is 17 dominant over ITCZ, SPCZ, and Asian monsoon region. AI is generally high over the 18 Asian monsoon region, but low over ITCZ and SPCZ regions. As suggested by these 19 patterns, aerosols, cloud, and meteorological conditions of our study region have strong 20 spatial variations, especially over ITCZ, SPCZ, and Asian monsoon region. 
1 To understand the spatio-temporal variations of aerosol, cloud, and meteorological 2 parameters, we performed spectral analysis in this study. The three-dimensional data

3 (latitude, longitude, and time axes) are converted into two dimensions by taking 4 latitudinal average along longitudinal direction. Since these data have different units, each 5 is normalized by its maximum value. Then a Fast Fourier Transform (FFT) is applied to 6 the time series data of each longitude grid to obtain the power spectrum shown in Figure 7 S2. The longitudes are expressed in zonal wave numbers with a positive (negative) value 8 indicating eastward (westward) propagation. Figure S2 suggests that the time series of 9 meteorological parameters and cloud properties are dominated by low-frequency signals 10 with period $(T)>2.5$ days; whereas, AI variation is dominated by signals with $T>5$ days. 11 For $T>5$ days, wave propagations both in eastward and westward directions are dominant, 12 suggesting the mixed influences of eastward propagating Kelvin wave and westward 13 propagating equatorial Rossby wave that can have $T$ of $\sim 2.5-20$ days and $\sim 7-30$ days, 14 respectively (Kiladis et al., 2009). Besides the two waves, the variations associated with 15 ITCZ, SPCZ, and Asian monsoon region also contribute to the spatio-temporal variations 16 on aerosols, clouds, and meteorological parameters (Jiang and Waliser, 2009; Zhao et al., 17 2018) as presented in Figure S2. Such natural phenomena (external factors) can affect the 18 atmosphere on the scale of thousands of $\mathrm{km}^{2}$; whereas, aerosol-cloud interaction can 19 occur on the scale of hundreds of $\mathrm{km}^{2}$. The spatio-temporal variations caused by those 20 external factors can overshadow the aerosol-cloud interaction process, making it 21 important to identify and remove their effects while studying aerosol effects on DCC. 


\section{$1 \quad$ Figures}
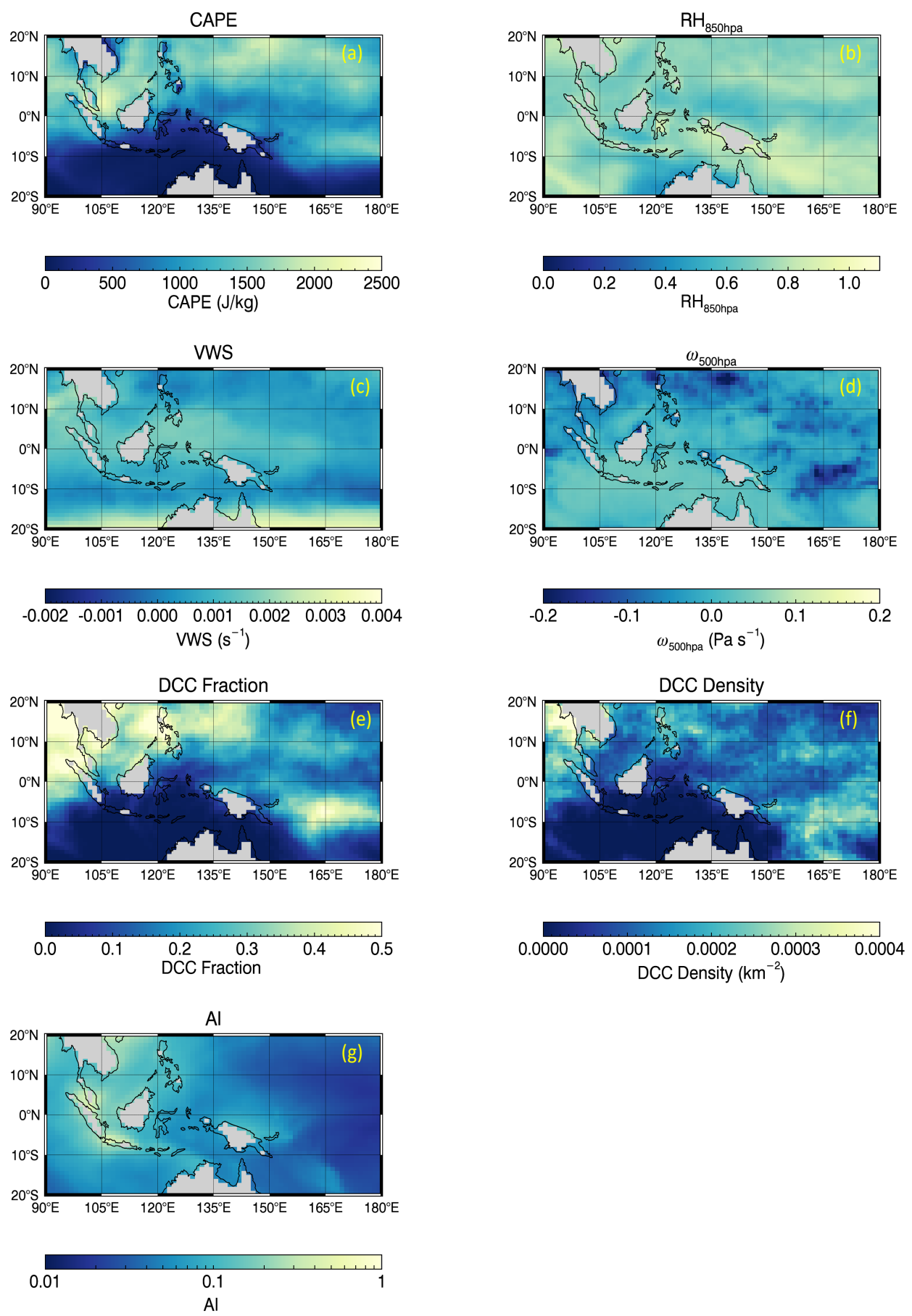

3 Figure S1. Monthly averages of (a) CAPE, (b) RH850hpa, (c) VWS, (d) W500hpa, (e) DCC

4 fraction, (f) DCC density, and (g) AI. 

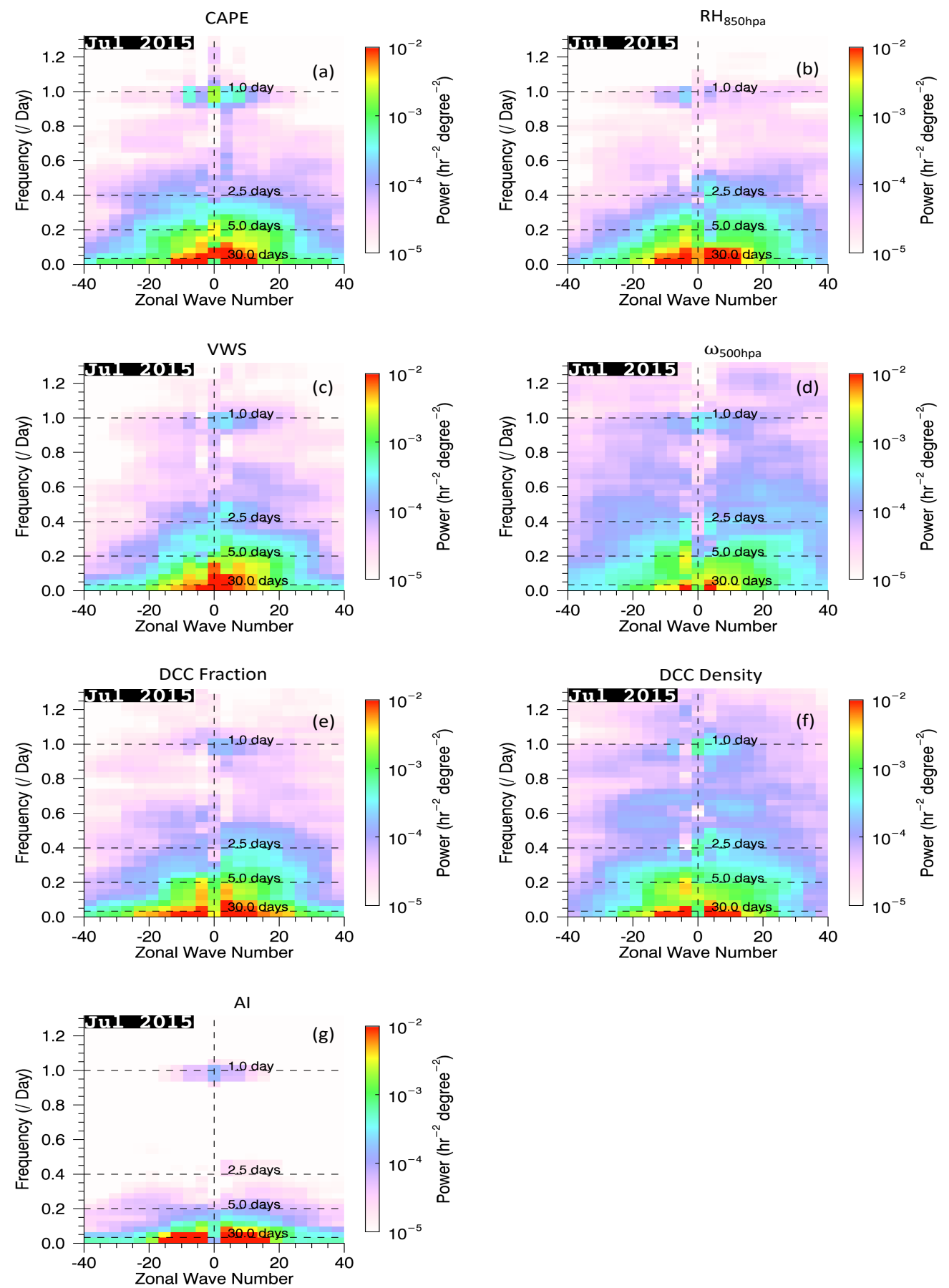

2 Figure S2. Spatio-temporal spectrum analyses for (a) CAPE, (b) $\mathrm{RH}_{850 \mathrm{hpa}}$, (c) VWS, (d)

3 W500hpa, (e) DCC fraction, (f) DCC density, and (g) AI. The positive and negative zonal

4 wave numbers denote eastward and westward propagations, respectively. 
2 Supplement II: Bootstrap method for mean values with confidence interval

A bootstrap method is a technique to estimate statistics of a population by sampling

4 data randomly with replacement. The bootstrap method used in this study is described 5 below:

6 Let us assume a data sample $X$ of $n$ elements, such as $\mathrm{X}=\left\{\mathrm{x}_{1}, \mathrm{x}_{2}, \ldots \mathrm{x}_{\mathrm{n}}\right\}$. From $X$, we 7 generated $m$ bootstrap samples each with $n$ elements by randomly taking the elements of

$8 X$ with replacement. $m$ in this study was set to 1000 . Each bootstrap samples were then

9 averaged to generate $m$ sets of mean and standard deviation values denoted by $\mu_{m}$ and $\sigma_{m}$,

10 respectively. The overall mean $(\mu)$ and standard deviation $(\sigma)$ values were calculated by

11 further averaging the values of $\mu_{m}$ and $\sigma_{m}$, respectively. Finally, the $95 \%$ confidence

12 interval was estimated as $\mu \pm z_{\alpha / 2} \sigma / \sqrt{m}$,where $\alpha=(1-0.95) / 2$ and $z_{\alpha / 2}$ is the

13 z-score value for $m$-1 degree of freedom. 


\section{$1 \quad$ References}

2 Jiang, X. and D. E. Waliser, 2009 : Two dominant subseasonal variability modes of the eastern Pacific ITCZ. Geophys. Res. Lett., 36, doi: 10.1029/2008GL036820.

4 Kiladis, G. N., M. C. Wheeler, P. T. Haertel, K. H. Straub, and P. E. Roundy, 2009 : Convectively coupled equatorial waves. Rev., Geophys., 47, 6 doi:10.1029/2008RG000266.

7 Zhao, B., K.-N. Liou, Y. Gu, J. H. Jiang, Q. Li, R. Fu, L. Huang, X. Liu, X. Shi, H. Su, et al., 2018 : Impact of aerosols on ice crystal size. Atmos. Chem. Phys.,, 18, 10651078, doi: 10.5194/acp-18-1065-2018. 